\title{
Induction melting of $\gamma$-TiAl in CaO crucibles
}

\author{
F. Gomes ${ }^{a}$, Joaquim Barbosa ${ }^{\mathrm{a}, *}$, C. Silva Ribeiro ${ }^{\mathrm{b}, 1}$ \\ ${ }^{a}$ Universidade do Minho, Departamento de Engenharia Mecânica, Campus de Azurém, 4800-058 Guimarães, Portugal \\ ${ }^{\mathrm{b}}$ FEUP, Departamento de Engenharia Metalúrgica e Materiais, Rua Roberto Frias, 4200-065 Porto, Portugal
}

\section{A R T I C L E I N F O}

\section{Article history:}

Received 10 July 2008

Received in revised form 29 July 2008

Accepted 20 August 2008

Available online 22 October 2008

\section{Keywords:}

A. Titanium aluminides, based on TiAl

C. Casting

C. Melting

D. Microstructure

\begin{abstract}
A B S T R A C T
In this work a Ti-48Al alloy was induction melted in a $\mathrm{CaO}$ crucible using different superheating temperatures. In the first stage, samples were allowed to cool to room temperature inside the crucibles, in order to simulate a low cooling rate, and in the second stage samples were centrifugally poured into a steel mould, in order to study the effect of the melting operation on the alloy contamination with oxygen. The effect of superheating temperature on the metal-crucible interaction, alloy chemical composition, microstructure and microhardness is evaluated. The $\mathrm{CaO}$ crucible was found to be slightly dissolved by the molten alloy and the extent of that dissolution depends on the superheating temperature. A relationship was found between oxygen concentration and microhardness profiles of the $\alpha_{2}+\gamma$ microconstituent, from the surface to the inside of samples, which depends on the superheating temperature and cooling rate.
\end{abstract}

(c) 2008 Elsevier Ltd. All rights reserved.

\section{Introduction}

Gamma titanium aluminides are the most serious candidates to replace traditional steels and Fe or Ni-based superalloys for high temperature applications, mainly in those areas where the combination of high tensile properties, creep strength and corrosion resistance, associated with superior strength-to-weight ratio are important, and cost is not a crucial factor, like aeronautical, aerospace and military equipments [1-3].

A major effort has been made over the last years to introduce titanium aluminides into the market-place as engineering components, however only a few niche markets in the automotive industry have been established [4,5]. Regarding aeronautical applications, although engine testing has been carried out by RollsRoyce, P \& W and GE no component made of a TiAl-based alloy is in use in any current aero engine [6,7].

At the present stage, the main factors limiting the manufacture of mass market TiAl-based components are the intrinsic characteristics of TiAl alloys - microstructure and chemical heterogeneity, brittleness, low room temperature ductility and poor hot workability [3], and the high production costs. Nevertheless, significant improvements are being made to improve the mechanical performance of these alloys, with the development of new ternary and quaternary TiAl-based alloys, namely those from the systems Ti$\mathrm{Al}-\mathrm{Nb}-\mathrm{Cr}$ and $\mathrm{Ti}-\mathrm{Al}-\mathrm{W}-\mathrm{Si}[6,8]$. To decrease production costs it is

\footnotetext{
* Corresponding author. Tel.: +351 253510220; fax: +351 253516007.

E-mail address: kim@dem.uminho.pt (J. Barbosa).

1 Tel.: +351 222041786; fax: +351222041792.
}

imperative to improve the actual processing techniques of TiAl. Present production routes of TiAl components are limited to forging and rolling, powder metallurgy and casting. The first two are very prone to chemical and microstructure heterogeneity and powder metallurgy is highly expensive and limited to simple geometries. Casting, using induction skull melting and the investment casting moulding process is the most versatile technology to manufacture intermetallic components. However, induction skull melting has a high impact in the castings final cost and in the high level of castings rejections, mainly due to the difficulty to achieve suitable superheating. To overcome this problem, high mould preheat temperatures are frequently used, thus increasing the probability of a metal-mould reaction occurring, and consequent metal contamination and development of solidification defects.

A possible way to reduce production costs might be the use of the ceramic crucible induction melting process, using suitable and low cost ceramic materials for crucible production, combined with the use of traditional melting stocks, avoiding expensive master alloys [9-11]. However this would only be possible in those cases where high melting point constituents like $\mathrm{Nb}$ or $\mathrm{W}$, for example, are not used in the melting stock or their concentration in the cast alloy is low enough to avoid prolonged heating at high temperature, and consequent excessive oxygen pickup from the crucible wall.

Until now, no material was found to be absolutely inert against titanium alloys and during melting some interaction between the alloy and the crucible materials always occurs, leading to metal contamination [10-12]. Taking into account the free Gibbs energy of formation, $\mathrm{CaO}$ presents the most negative value among all 


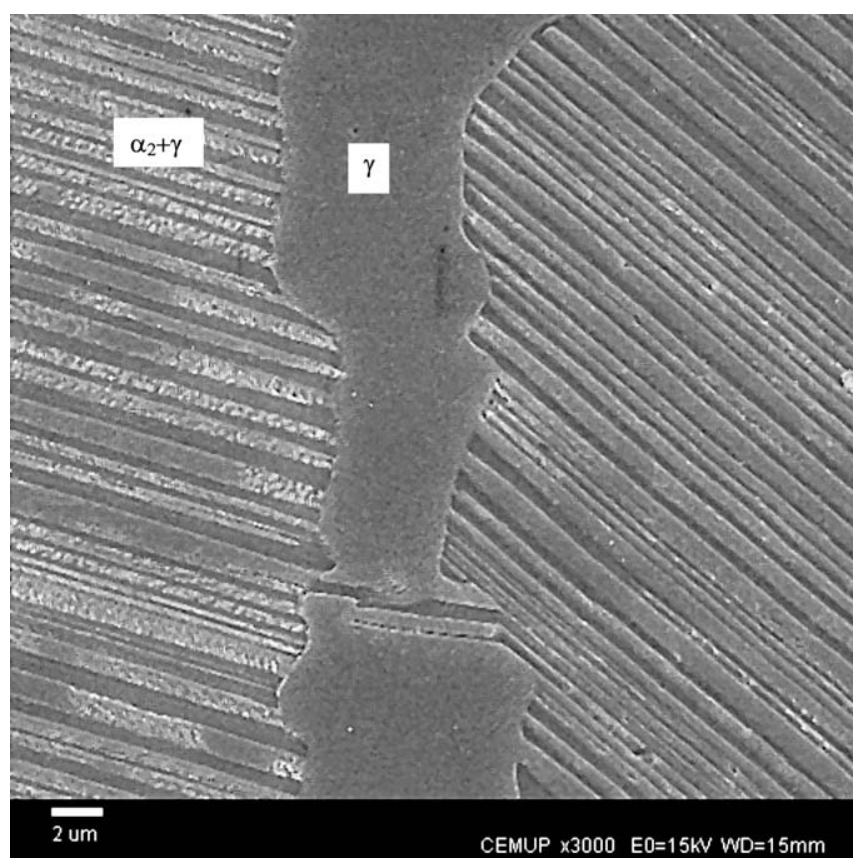

Fig. 1. Microstructure of a Ti-48Al sample, induction melted in a $\mathrm{CaO}$ crucible.

metallic oxides if $\mathrm{Y}_{2} \mathrm{O}_{3}$ is excluded, suggesting that it could be a good option to produce melting crucibles for titanium alloys.

\section{Experimental}

A Ti-48Al alloy was selected for melting, prepared from commercially pure titanium and aluminium. Melting stocks weighing $1.3 \times 10^{-1} \mathrm{~kg}$ were melted in a ceramic crucible induction melting furnace equipped with a commercially available $0.15 \mathrm{l} \mathrm{CaO}$ crucible, under a dry argon atmosphere at $10^{-1}$ bar. Before the heating cycle, the chamber was evacuated up to $10^{-3}$ bar and backfilled with argon 5 times, in order to reduce the oxygen content to a minimum level. The superheating temperatures were $1550{ }^{\circ} \mathrm{C}$ and $1600^{\circ} \mathrm{C}$, measured with a type $\mathrm{B}$ (Pt-PtRd) thermocouple with a $\mathrm{Mo}-\mathrm{Al}_{2} \mathrm{O}_{3}$ protection sheath, corresponding to approximately 50 and $100{ }^{\circ} \mathrm{C}$ superheating (assuming that the liquidus temperature of $\mathrm{Ti}-48 \mathrm{Al}$ is $\left.1500{ }^{\circ} \mathrm{C}[13]\right)$. After reaching the superheating temperature the alloy was held at that temperature for $60 \mathrm{~s}$ in order to get chemical homogenization. In the first series of tests, samples were allowed to solidify and cool to room temperature inside the crucible, in order to simulate the worst practical situation concerning the occurrence of a metal-crucible interaction. In the second series of tests, $20 \mathrm{~mm} \times 80 \mathrm{~mm}$ test samples were centrifugally poured at $400 \mathrm{rpm}$ into a cylindrical steel mould pre-heated to $250^{\circ} \mathrm{C}$, in order to isolate the effect of oxygen pickup exclusively from the crucible, during the melting operation.

During cooling, temperature measurement was performed using a wireless receiver/transmitter-receiver data acquisition system compatible with the centrifugal casting process, developed at the University of Minho.

Samples for characterization were collected from the middle of the cast cylinders by sectioning them at $50 \%$ of their height. Phase identification and chemical composition were performed by quantitative EDS analysis with standards of pure Ti, Al and Ca using a JEOL JSM 35C scanning electron microscope. Overall oxygen content was measured by the IGF technique (Inert Gas Fusion), and SIMS (Secondary Ion Mass Spectrometry) was used to determine the diffusion profile of oxygen from the surface to the inside of the samples. Microhardness was evaluated on a Shimadzu hardness tester using a $50 \mathrm{~g}$ load for $15 \mathrm{~s}$.

\section{Results}

\subsection{Microstructure}

Those samples allowed to cool inside the crucible revealed a microstructure containing a dendritic lamellar constituent with two phases $-\alpha_{2}+\gamma-$ and an interdendritic $\gamma$ phase (Fig. 1). The volume fraction of the lamellar constituent was higher near the surface in every sample (fully lamellar at distances from the surface lower than $25 \mu \mathrm{m}$ ) and decreased towards the inside of them where average values between 70.5 and $75 \%$ were found, following the decrease in the cooling rate. This is the typical TiAl biphase structure $\left(\alpha_{2}+\gamma\right)$ in which the amount of aluminium is slightly below $49 \%$, and the amount of $\gamma$ constituent increases with increasing $\mathrm{Al}$ content $[3,12,14]$. In those samples poured into steel moulds the microstructure was fully lamellar at distances from the surface of less than $200 \mu \mathrm{m}$ (Fig. 2) due to the high cooling rate achieved in the metallic mould (Fig. 3). At higher distances from the surface small grains of $\gamma$ phase appear at the boundaries of the lamellar grains, in a volume fraction between 5 and $10 \%$.

\subsection{Chemical composition}

Table 1 presents the chemical composition of cast samples at different distances from the surface, for each pair of temperature/ cooling media. After melting, a very small amount of aluminium powder usually appeared at the furnace window (cold zone), suggesting that some Al vaporization occurred, but there was no

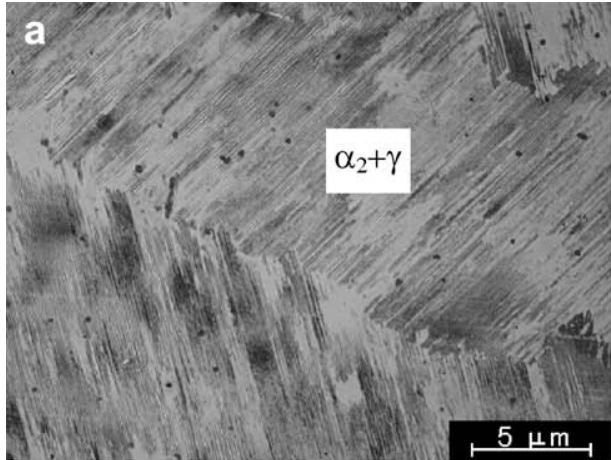

$50 \mu \mathrm{m}$ from the sample surface

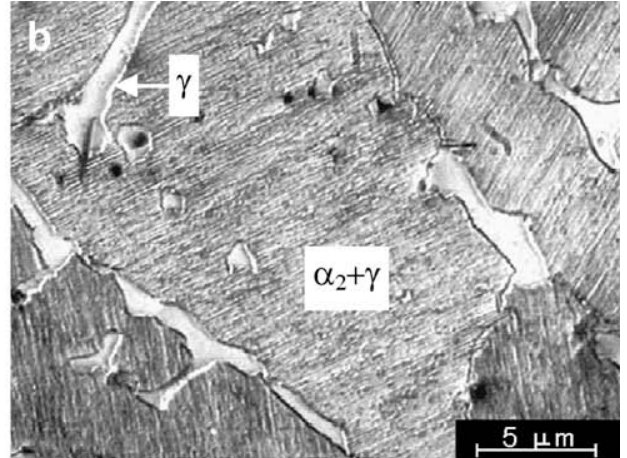

$250 \mu \mathrm{m}$ from the sample surface

Fig. 2. Microstructure of Ti-48Al samples cast in steel moulds, at different distances from surface 


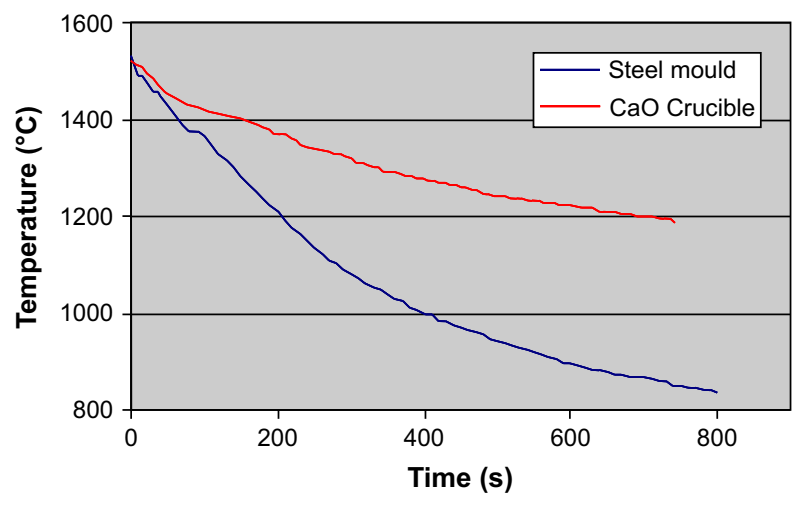

Fig. 3. Cooling curves of samples allowed to solidify inside $\mathrm{CaO}$ crucibles and steel moulds.

perceptible aluminium loss in the alloy composition, which fall within the range it was expected. Although a stronger exothermic reaction between $\mathrm{Al}$ and $\mathrm{Ti}$ could be expected, it might have been avoided due to the fact that $\mathrm{Al}$ never reached the liquid stage, but kept on a mushy state since the early moments of the melting operation, as it immediately started dissolving Ti.

In every sample the lamellar dendritic constituent was richer in titanium and the interdendritic $\gamma$ phase had higher aluminium content, which agrees with the available references [3,8,15]. Every sample revealed a slight contamination with Ca that dissolved in both microconstituents, although a little more in the interdendritic $\gamma$ phase.

In samples allowed to solidify inside the crucible (samples S1 and S2), Ca concentration was higher at the surface assuming constant values for distances from the surface higher than $25 \mu \mathrm{m}$ for $T=1550{ }^{\circ} \mathrm{C}$ and $50 \mu \mathrm{m}$ for $T=1600^{\circ} \mathrm{C}$. In those samples poured in steel moulds, no Ca concentration gradients were found, and a constant value around $0.10 \mathrm{wt} \%$ was found in the sample poured at $1600{ }^{\circ} \mathrm{C}$, and values below the equipment detection limit in the sample poured at $1550{ }^{\circ} \mathrm{C}$. Besides $\mathrm{Ca}$, the cast alloys were found to be contaminated with oxygen, whose content and concentration gradients were found to depend on the superheating temperature and the cooling media (Table 1 and Fig. 4).

\subsection{Microhardness}

Microhardness values of the $\alpha_{2}+\gamma$ microconstituent were affected both by the cooling media and the superheating temperature, but in the $\gamma$ phase they were almost constant and similar in every sample (289-293 HV). In those samples allowed to solidify inside the crucibles, microhardness of $\alpha_{2}+\gamma$ decreased from the surface to the inside of samples for both superheating temperatures (Fig. 5), until a certain distance from surface, which corresponds to the alpha-case extension. For higher distances from the surface, microhardness assumes almost constant values, of the same magnitude of those in bulk. For sample $\mathrm{S} 1$, poured at $1550^{\circ} \mathrm{C}$, that value is around $45 \mu \mathrm{m}$, and for sample S2, poured at $1600^{\circ} \mathrm{C}$, it is around $70 \mu \mathrm{m}$. This gradient did not occur in samples poured in steel moulds, which revealed almost constant microhardness values all over their mass. The cooling media and the superheating temperature also affected the $\alpha_{2}+\gamma$ microhardness in the bulk of samples: average values of 303 and $316 \mathrm{HV}$ for $1550^{\circ} \mathrm{C}$ and $1600^{\circ} \mathrm{C}$ respectively in those samples allowed to cool inside the crucible (S1 and S2), and 301 and $306 \mathrm{HV}$, for the same temperatures, in those samples poured into steel moulds (S3 and S4) (see Table 2).

Table 1

Chemical composition of cast Ti-48Al samples poured at different superheating temperatures and cooled in different cooling media

\begin{tabular}{|c|c|c|c|c|c|c|c|c|c|c|c|c|}
\hline \multirow[b]{2}{*}{ Sample } & \multirow[b]{2}{*}{ Const. } & \multirow[b]{2}{*}{ Element } & \multicolumn{10}{|c|}{ Depth from surface $(\mu \mathrm{m})$} \\
\hline & & & 25 & 50 & 100 & 150 & 200 & 250 & 300 & 500 & 1000 & Bulk \\
\hline S1 & $\alpha_{2}+\gamma$ & $\mathrm{Ti}$ & 51.6 & 50.2 & 51.7 & 51.9 & 52.6 & 52.0 & 51.9 & 52.0 & 52.5 & 52.7 \\
\hline \multirow[t]{2}{*}{$1550^{\circ} \mathrm{C}$} & & $\mathrm{Al}$ & 48.3 & 49.8 & 48.3 & 48.1 & 47.4 & 48.0 & 48.1 & 48.0 & 47.5 & 47.3 \\
\hline & & $\mathrm{Ca}$ & 0.10 & $<0.10$ & $<0.10$ & $<0.10$ & $<0.10$ & $<0.10$ & $<0.10$ & $<0.10$ & $<0.10$ & $<0.10$ \\
\hline \multirow[t]{3}{*}{ Crucible } & $\gamma$ & $\mathrm{Ti}$ & 45.0 & 44.9 & 46.5 & 46.0 & 45.8 & 45.9 & 45.9 & 46.5 & 45.8 & 45.6 \\
\hline & & $\mathrm{Al}$ & 54.7 & 55.0 & 53.5 & 54.0 & 54.2 & 54.1 & 54.1 & 53.5 & 54.2 & 54.4 \\
\hline & & $\mathrm{Ca}$ & 0.14 & $<0.10$ & $<0.10$ & $<0.10$ & $<0.10$ & $<0.10$ & $<0.10$ & $<0.10$ & $<0.10$ & $<0.10$ \\
\hline \multicolumn{4}{|c|}{ Sample average composition: } & \multicolumn{2}{|c|}{$\mathrm{Ti}-51.7$} & \multicolumn{2}{|c|}{$\mathrm{Al}-48.3$} & \multicolumn{2}{|c|}{$\mathrm{Ca}<0.1$} & \multicolumn{3}{|c|}{ Oxygen content -0.26 wt $\%$} \\
\hline S2 & \multirow[t]{3}{*}{$\alpha_{2}+\gamma$} & $\mathrm{Ti}$ & 52.1 & 51.6 & 51.7 & 51.5 & 52.0 & 51.8 & 51.8 & 52.3 & 52.2 & 52.5 \\
\hline \multirow[t]{2}{*}{$1600^{\circ} \mathrm{C}$} & & $\mathrm{Al}$ & 47.8 & 48.4 & 48.3 & 48.5 & 48.0 & 48.2 & 48.2 & 47.7 & 47.8 & 47.5 \\
\hline & & $\mathrm{Ca}$ & 0.12 & $<0.10$ & $<0.10$ & $<0.10$ & $<0.10$ & $<0.10$ & $<0.10$ & $<0.10$ & $<0.10$ & $<0.10$ \\
\hline \multirow[t]{3}{*}{ Crucible } & \multirow[t]{3}{*}{$\gamma$} & $\mathrm{Ti}$ & 46.2 & 45.4 & 45.8 & 45.8 & 45.9 & 46.3 & 45.5 & 46.1 & 46 & 45.9 \\
\hline & & $\mathrm{Al}$ & 53.6 & 54.5 & 54.1 & 54.2 & 54.0 & 53.6 & 54.5 & 53.9 & 53.9 & 54.0 \\
\hline & & $\mathrm{Ca}$ & 0.16 & 0.11 & 0.10 & $<0.10$ & 0.11 & 0.11 & $<0.10$ & $<0.10$ & 0.11 & 0.10 \\
\hline \multicolumn{4}{|c|}{ Sample average composition: } & \multicolumn{2}{|c|}{$\mathrm{Ti}-52.1$} & \multicolumn{2}{|c|}{$\mathrm{Al}-47.8$} & \multicolumn{2}{|c|}{$\mathrm{Ca}-0.11$} & \multicolumn{3}{|c|}{ Oxygen content -0.29 wt $\%$} \\
\hline S3 & \multirow[t]{3}{*}{$\alpha_{2}+\gamma$} & $\mathrm{Ti}$ & 51.4 & 51.2 & 52.1 & 52.2 & 51.9 & 51.7 & 52.3 & 52.3 & 52.1 & 52.2 \\
\hline \multirow[t]{2}{*}{$1550^{\circ} \mathrm{C}$} & & $\mathrm{Al}$ & 48.6 & 48.8 & 47.9 & 47.8 & 48.1 & 48.3 & 47.7 & 47.7 & 47.9 & 47.8 \\
\hline & & $\mathrm{Ca}$ & $<0.10$ & $<0.10$ & $<0.10$ & $<0.10$ & $<0.10$ & $<0.10$ & $<0.10$ & $<0.10$ & $<0.10$ & $<0.10$ \\
\hline \multirow[t]{3}{*}{ Steel mould } & \multirow[t]{3}{*}{$\gamma$} & $\mathrm{Ti}$ & 45.5 & 44.9 & 45.2 & 46.1 & 46.0 & 45.5 & 45.9 & 46.3 & 45.5 & 45.9 \\
\hline & & $\mathrm{Al}$ & 54.4 & 55.0 & 54.8 & 53.9 & 54.0 & 54.5 & 54.1 & 53.7 & 54.5 & 54.1 \\
\hline & & $\mathrm{Ca}$ & n.a. & n.a. & n.a. & n.a. & $<0.10$ & $<0.10$ & $<0.10$ & $<0.10$ & $<0.10$ & 0.10 \\
\hline \multicolumn{3}{|c|}{ Sample average composition: } & & \multicolumn{2}{|c|}{$\mathrm{Ti}-51.9$} & \multicolumn{2}{|c|}{$\mathrm{Al}-48.1$} & \multicolumn{2}{|c|}{$\mathrm{Ca}<0.1$} & Oxyger & $n t-0.2$ & \\
\hline S4 & $\alpha_{2}+\gamma$ & $\mathrm{Ti}$ & 51.2 & 52.2 & 52.0 & 52.8 & 52.9 & 52.7 & 51.2 & 52.8 & 52.5 & 53.0 \\
\hline $1600^{\circ} \mathrm{C}$ & & $\mathrm{Al}$ & 48.8 & 47.7 & 48.0 & 47.2 & 47.1 & 47.3 & 48.8 & 47.2 & 47.5 & 47.0 \\
\hline & & $\mathrm{Ca}$ & $<0.10$ & $<0.10$ & $<0.10$ & $<0.10$ & $<0.10$ & $<0.10$ & $<0.10$ & $<0.10$ & $<0.10$ & $<0.10$ \\
\hline Steel mould & $\gamma$ & $\mathrm{Ti}$ & 45.0 & 44.9 & 45.2 & 45 & 45.6 & 46.7 & 46.0 & 46.4 & 45.5 & 46.4 \\
\hline & & $\mathrm{Al}$ & 55.0 & 55.0 & 54.8 & 55.0 & 54.3 & 53.2 & 53.9 & 53.5 & 54.5 & 53.5 \\
\hline & & $\mathrm{Ca}$ & n.a. & n.a. & n.a. & n.a. & 0.10 & 0.10 & 0.10 & 0.11 & 0.10 & 0.10 \\
\hline Sample avera & omposition: & & & $\mathrm{Ti}-5$ & & $\mathrm{Al}-4$ & & $\mathrm{Ca}-0$ & & Oxyger & $\mathrm{nt}-0.2$ & \\
\hline
\end{tabular}




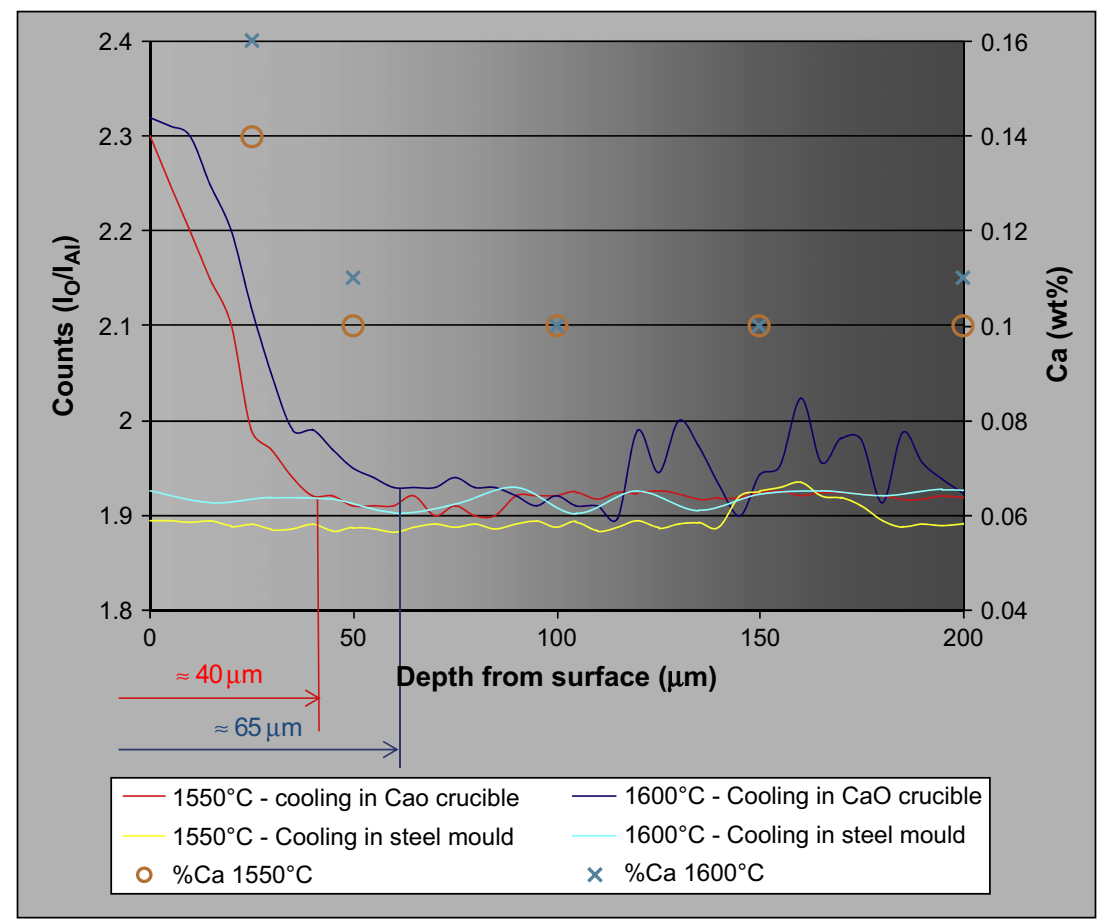

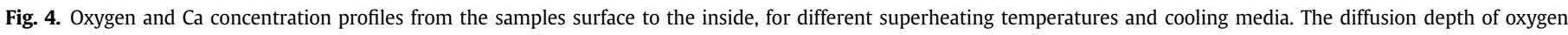

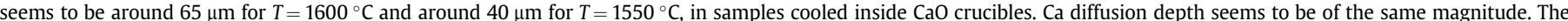

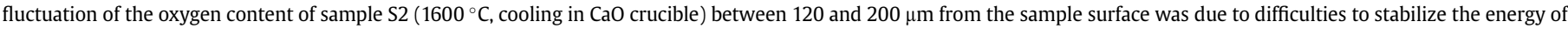
the primary $\mathrm{Ar}^{+}$ion beam source during the corresponding lap time.

\subsection{Metal-crucible/mould interface}

Fig. 6 shows the samples microstructure at the metal-crucible wall and metal-steel mould interfaces for $1550{ }^{\circ} \mathrm{C}$ pouring temperature. Those samples allowed to solidify inside the crucible revealed a continuous film of calcium oxide at the surface with average thickness less than $5 \mu \mathrm{m}$. This layer could be easily removed with a finger, revealing that no metal penetration occurred at the crucible wall. The morphology and thickness of that layer were not affected by the superheating temperature.

\section{Discussion}

The average chemical composition of every sample was very close to the desired Ti-48Al standard alloy, as presented in Table 1, suggesting that vacuum induction melting could provide good homogenization of the melted feed stocks. However, the presence of $\mathrm{Ca}$ and $\mathrm{O}$ in solution reveals that some sort of interaction occurred between the $\mathrm{CaO}$ crucible and the cast alloy. According to its free energy of formation, $\mathrm{CaO}$ is thermodynamically much more stable than titanium and aluminium oxides, so no reaction of the crucible with the cast alloy should be expected. Thus, the most probable cause of alloy contamination is the dissolution of the $\mathrm{CaO}$ crucible by the metal, which confirms the results of other researchers [9].

The dissolution of the $\mathrm{CaO}$ crucible can be confirmed by the oxygen content of the alloys. According to the composition of the melting stock, the maximum oxygen content of the alloys should be $0.16 \mathrm{wt} \%$. Nevertheless, the oxygen content of the cast samples varies from $0.26 \mathrm{wt} \%$ to $0.29 \mathrm{wt} \%$ in those samples cooled inside the $\mathrm{CaO}$ crucibles (0.10-0.13 wt\% enrichment, depending on the superheating temperature), and between $0.24 \mathrm{wt} \%$ and $0.26 \mathrm{wt} \%$ in samples poured into steel moulds $(0.08-0.10 \mathrm{wt} \%$ enrichment for 1550 and $1600{ }^{\circ} \mathrm{C}$ superheating temperature, respectively) (see Table 2). Taking into account that the entire processing (melting + pouring/cooling) was performed under a dry argon atmosphere, which excludes the possibility of oxygen pickup, the only possible source of oxygen was the crucible material. The values presented above are slightly higher $(\approx 0.03 \mathrm{wt} \%)$ than those referred by Barbosa et al. [11] and Kuang et al. [16] for Ti-48Al obtained in $\mathrm{Y}_{2} \mathrm{O}_{3}$ crucibles using the same superheating
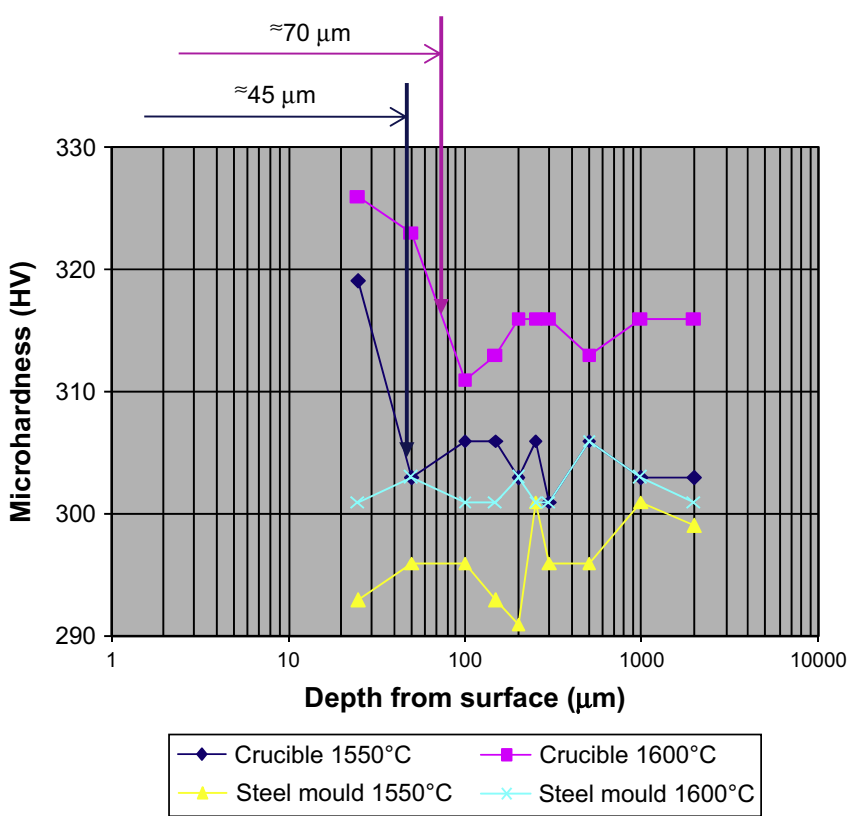

Fig. 5. Microhardness variation at the $\alpha_{2}+\gamma$ microconstituent in Ti-48Al samples allowed to solidify inside the crucibles and poured into steel dies, for different superheating temperatures. 
Table 2

Influence of superheating and cooling media in some characteristics of $\mathrm{Ti}-48 \mathrm{Al}$ samples induction melted in $\mathrm{CaO}$ crucibles

\begin{tabular}{|c|c|c|c|c|c|c|c|c|c|}
\hline \multirow[t]{3}{*}{ Temp. $\left({ }^{\circ} \mathrm{C}\right)$} & \multirow[t]{3}{*}{ Cooling media } & \multirow[t]{3}{*}{ Alpha-case extension ( $\mu \mathrm{m})$} & \multicolumn{7}{|c|}{ Inside the sample } \\
\hline & & & \multicolumn{3}{|c|}{ Composition (at\%) } & \multicolumn{2}{|c|}{ Dissolved oxygen (wt\%) } & \multicolumn{2}{|c|}{ Microhardness (HV) } \\
\hline & & & $\mathrm{Ti}$ & $\mathrm{Al}$ & $\mathrm{Ca}$ & Final & Pickup & $\alpha_{2}+\gamma$ & $\gamma$ \\
\hline \multirow[t]{2}{*}{1550} & S1 crucible & $\approx 40$ & 51.7 & 48.3 & $<0.1$ & 0.26 & 0.10 & 303 & 291 \\
\hline & S3 steel mould & - & 51.9 & 48.1 & $<0.1$ & 0.24 & 0.08 & 301 & 291 \\
\hline \multirow[t]{2}{*}{1600} & S2 crucible & $\approx 70$ & 52.1 & 47.8 & 0.11 & 0.29 & 0.13 & 316 & 289 \\
\hline & S4 steel mould & - & 52.3 & 47.6 & 0.10 & 0.26 & 0.10 & 306 & 293 \\
\hline
\end{tabular}

temperatures, and are similar to those obtained by Sato et al. (0.2$0.4 \mathrm{wt} \%$ ) [17] and Liu et al. (0.082-0.29 wt\%) [9] for CaO crucible induction melted unalloyed titanium and $\mathrm{Ti}-45 \mathrm{Al}-8 \mathrm{Nb}$ respectively.

According to Fig. 4 and Table 1, the oxygen and calcium contents of samples allowed to solidify inside the crucibles decrease from the surface to the inside of the samples following curves with similar profiles, for the same superheating temperatures. This behaviour suggests that the extent of the $\mathrm{CaO}$ crucible dissolution is a function of that parameter. When the metal reached the liquid state and its fluidity became high enough, it could easily penetrate the interstices between the $\mathrm{CaO}$ grains (notice that $\mathrm{CaO}$ crucibles used on this work had $20 \%$ open porosity), thus increasing the erosion effect and the grain dissolution rate. Although the stirring effect of induction heating was not very high due to the high frequency of the melting furnace $(1.3 \mathrm{MHz})$, it helped in the distribution of those $\mathrm{CaO}$ particles detached from the crucible in the liquid metal, which dissolved them, and the dissolution products ( $\mathrm{Ca}$ and $\mathrm{O}$ ) went into solution with the alloy. Thus, a uniform composition was easily reached in the molten alloy, the value of which depended on the dissolution extent and in turn on the melt temperature. That is why the average oxygen enrichment is higher in those samples superheated to $1600{ }^{\circ} \mathrm{C}$ (samples S2 and S4). However, when the heating supply stopped and cooling started, the metal fluidity decreased very quickly and the $\mathrm{CaO}$ dissolution rate became much slower, as well as the diffusion mechanisms, leading to the $\mathrm{Ca}$ and $\mathrm{O}$ concentration gradients found in samples S1 and S2. Nevertheless, until the metal solidifies, diffusion of $\mathrm{Ca}$ and $\mathrm{O}$ is still possible, slightly increasing the $\mathrm{Ca}$ and $\mathrm{O}$ content inside the samples. However, due to different crucible temperatures, the cooling conditions were not the same for every sample. As a consequence, they led to different dissolution kinetics and diffusion rates, thus to different average contents and concentration gradients of $\mathrm{Ca}$ and $\mathrm{O}$ from the surface to the inside of the cast samples.

Results obtained by allowing the alloys to solidify inside the melting crucibles can be a useful indication for the use of $\mathrm{CaO}$ to produce ceramic moulds for TiAl. In fact, it can be assumed that if
$\mathrm{CaO}$ moulds are used for TiAl castings, the maximum alloy contamination, "alpha-case" extension and microhardness will be those obtained by allowing the alloy to solidify inside the crucible (samples S1 and S2) as in practice the cooling rate will be much higher due to the lower mould temperature (for samples S1 and S2, the crucible acted as a mould, thus the "mould" temperature was in fact 1550 and $1600{ }^{\circ} \mathrm{C}$ respectively). Nevertheless, due to the hygroscopic nature of $\mathrm{CaO}$, its use as mould material will always have to be done with great care to avoid moisture pickup, otherwise mould destruction and unacceptable oxygen pickup by the cast alloy will easily occur. Although some researchers claim to have successfully produced automotive components using $\mathrm{CaO}$ moulds, it is believed that if a suitable handling technique of this material will not be developed, the use of $\mathrm{CaO}$ moulds will always be limited to non-critical applications.

The oxygen content of the cast alloys is the main factor responsible for microhardness variation as it dissolves interstitially in the matrix. For such reason, the microhardness of the $\alpha_{2}+\gamma$ constituent and oxygen concentration profiles of samples allowed to solidify inside the $\mathrm{CaO}$ crucibles are quite similar, decreasing from the sample surface inwards, reaching constant values after similar distances from the sample surface (see Figs. 4 and 5). In the $\gamma$ phase the microhardness is quite constant for every cast sample because oxygen dissolves preferentially in the lamellar constituent being almost constant in the $\gamma$ phase, where its solubility limit is around $230 \mathrm{ppm}$ [18]. As a consequence, if no other residual elements are present in solution, the microhardness variation profile in $\alpha_{2}+\gamma$ represents, in fact, the oxygen variation profile in the cast alloy. Due to such a strict relationship, the microhardness depends significantly on the superheating temperature and cooling rate, because as those parameters increase and decrease respectively, the more extensive is the crucible material dissolution, with a consequent increase in the alloy oxygen content. Although the microhardness increases at the surface, the maximum value $326 \mathrm{HV}$ - is significantly lower than those reported by other researchers for as cast Ti-48Al $[10,14]$ and agree with the suggested microhardness values for this kind of alloy [19].
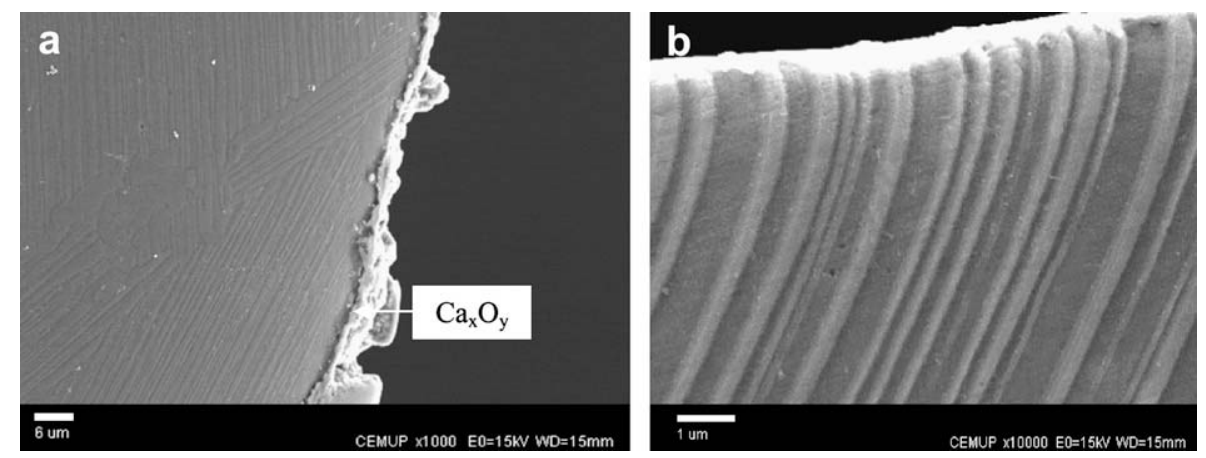

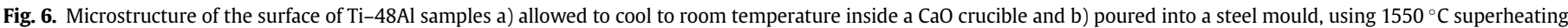
temperature. 


\section{Conclusions}

- For the processing conditions used in this work, it is possible to obtain cast $\mathrm{Ti}-48 \mathrm{Al}$ by melting commercially pure titanium and aluminium, using $1550^{\circ} \mathrm{C}$ superheating temperature for $60 \mathrm{~s}$;

- For superheating temperatures of 1550 and $1600^{\circ} \mathrm{C}$, melting in $\mathrm{CaO}$ crucibles led to oxygen enrichment of a Ti-48Al alloy between 0.08 and $0.10 \mathrm{wt} \%$, making it difficult to produce components for critical applications;

- Besides superheating, the cooling rate is an important factor in the interaction between $\mathrm{CaO}$ and molten $\mathrm{TiAl}$, with direct influence in the concentration of residual elements and microhardness;

- If $\mathrm{CaO}$ moulds and superheating temperatures up to $1600^{\circ} \mathrm{C}$ are used to produce TiAl castings the maximum "alpha-case" extension and surface microhardness that may be expected will be around $50 \mu \mathrm{m}$ and $326 \mathrm{HV}$, respectively. However, due to $\mathrm{CaO}$ hygroscopic nature, a suitable moulding technique has to be developed to avoid moisture pickup and consequent mould destruction and excessive alloy contamination with oxygen.

\section{Acknowledgements}

The authors want to acknowledge to Portuguese Foundation for Science and Technology for financially supporting this work, and to the Department of Mechanical Engineering of University of Minho, for the provision of research facilities.

\section{References}

[1] Cui WF, Liu CM, Bauer V, Christ HJ. Thermomechanical fatigue behaviours of a third generation $\gamma$-TiAl based alloy. Intermetallics 2007;15:675-8.
[2] Saaria H, Beddoesa J, Seob DY, Zhaob L. Development of directionally solidified $\gamma$-TiAl structures. Intermetallics 2005;13:937-43.

[3] Imayev RM, Imayev VM, Oehring M, Appel F. Alloy design concepts for refined gamma titanium aluminide based alloys. Intermetallics 2007;15: 451-60.

[4] McQuay PA, Sikka VK. Casting. In: Westbrook JH, Fleischer RL, editors. Intermetallic compounds - principles and practice, 3; 2000. p. 592-615.

[5] Tetsui T. Development of TiAl turbocharger for passenger vehicle. Materials Science and Engineering A 2002;329-331:582-8.

[6] Lasalmonie Alain. Intermetallics: why is it so difficult to introduce them in gas turbine engines? Intermetallics 2006;14:1123-9.

[7] Wu Xinhua. Review of alloy and process development of TiAl alloys. Intermetallics 2006;14:1114-22.

[8] Wang S, Guo P, Yang L. Centrifugal precision cast TiAl turbocharger wheel using ceramic mold. Journal of Materials Processing Technology 2007; doi:10.1016/j.jmatprotec.2008.01.062.

[9] Liu K, Ma YC, Gao M, Rao GB, Li YY, Wei K, et al. Single step centrifugal casting TiAl automotive valves. Intermetallics 2005;13:925-8.

[10] Si-Young Sung, Young-Jig Kim. Economic net-shape forming of TiAl alloys for automotive parts. Intermetallics 2006;14:1163-7.

[11] Barbosa J, Ribeiro CS, Monteiro C. Influence of superheating on casting of $\gamma$-TiAl. Intermetallics 2007;15:945-55.

[12] Barbosa J, Silva Ribeiro C, Monteiro C. Process for obtaining $\gamma$-TiAl pieces by casting, Patent Pending WO2005/025778 A1.

[13] Okamoto H. Binary alloys phase diagrams - aluminium - titanium system, CD-Rom. 2nd ed. ASM International; 1996.

[14] Jovanovic MT, Dimcic B, Bobic I, Zec S, Maksimovic V. Microstructure and mechanical properties of precision cast TiAl turbocharger wheel. Journal of Materials Processing Techno $\times \log y$ 2005;167:14-21.

[15] Ramanujan RV, Maziasz PJ, Liu CT. The thermal stability of the microstructure of $\gamma$-based titanium aluminides. Acta Materialia 1996:44(7):2611-42.

[16] Kuang JP, Harding RA, Campbell J. A study of refractories as crucible and mould materials for melting and casting y-TiAl alloys. International Journal of Cast Metals Research 2001;13:227-92.

[17] Sato T, Yoneda Y, Matsumoto N. A new process of producing titanium alloy castings. Transactions of the Japan Foundrymen's Society 1992;11:27-33.

[18] Menand A, Huguet A, Nérac-Partaix A. Interstitial solubility in $\gamma$ and $\alpha_{2}$ phases of TiAl-based alloys. Acta Materialia 1996;44(12):4729-37.

[19] Materials properties handbook - titanium alloys. Ohio: ASM; 1994. pp. 101134 (Section VI - Advanced Materials - Titanium Aluminides). 